\title{
UTILIZAÇÃO DE CONTRATOS FUTUROS DE COMMODITIES COMO FORMA DE OTIMIZAR CARTEIRAS DE INVESTIMENTOS DO MERCADO BRASILEIRO ${ }^{1}$
}

\section{USE OF COMMODITY FUTURES CONTRACTS AS A WAY TO OPTIMIZE INVESTMENT PORT- FOLIOS OF THE BRAZILIAN MARKET}

\author{
Marília Cordeiro Pinheiro \\ Mestra em Mercado Financeiro pela Universidade de Brasília (UnB) \\ Instituição em que trabalha \\ marilia.cordeiro90@hotmail.com
}

André Ricardo Moncaico Zanon

Mestre em Contabilidade e Mercado Financeiro pela Universidade de Brasília (UnB)

Banco Central do Brasil

zanonandre@gmail.com

José Alves Dantas

Doutor em Ciências Contábeis pela Universidade de Brasília (UnB)

Universidade de Brasília

josealvesdantas@unb.br

\section{Bruno Vinícius Ramos Fernandes}

Doutor em Ciências Contábeis pelo Programa Multi-institucional e Inter-regional de Pósgraduação em Ciências Contábeis - UnB/UFPB/UFRN

Universidade de Brasília

bv.ramos@gmail.com

\section{RESUMO}

Objetivo: Avaliar a eficácia da utilização de contratos futuros de commodities como mecanismo de otimização das carteiras de investimentos.

Fundamento: $O$ estudo apoia-se na teoria de diversificação do portfólio, com a premissa de que os investidores são avessos ao risco e com isso elaboram carteiras tangentes à fronteira de eficiência, com maior retorno esperado para determinado nível de risco.

Método: Foram compostas carteiras com contratos futuros de commodities e elaboradas cinco estratégias de investimentos com e sem esses contratos, utilizando os retornos esperados e a matriz de covariância para calcular os pesos dos ativos nas carteiras. A análise contempla o período de

\footnotetext{
${ }^{1}{ }_{1}$ Artigo recebido em: 03/11/2018. Revisado por pares em: 18/03/2019. Reformulado em: 16/05/2019. Recomendado para publicação: 16/05/2019 por Anna Paola Fernandes Freire (Editora Adjunto). Publicado em: 02/09/2019. Organização responsável pelo periódico: UFPB
} 
2011-2016 e os subperíodos de 2011-2013 e 2014-2016, caracterizados, respectivamente, por expansão e contração econômica.

Resultados: Os testes empíricos revelaram que (i) os portfólios com contratos futuros oferecem potencial de diversificação para carteiras compostas majoritariamente pelo mercado de ações (ii) apenas carteiras com contratos vendidos de café tocaram a zona de eficiência, de forma que os contratos de boi e milho não mostraram evidências de contribuição para otimização. (iii) carteiras compostas majoritariamente pelo IFIX, IAM-B, dólar e CDI foram as composições mais eficientes devido a particularidades do mercado de capital brasileiro, como alta taxa de juros, ambiente inflacionário e depreciação cambial durante o período.

Contribuições: Os resultados do estudo (i) fornecem perspectiva sobre o uso dos contratos futuros de commodities para reduzir ou não os riscos de portfólios de investimentos; (ii) destacam que esses resultados podem ser distintos em momentos de expansão ou retração econômica; (iii) corroboram estudos anteriores sobre o uso de contratos futuros de commodities para otimização de carteiras de ações, porém se diferenciando quando levada essa análise para ativos imobiliários e títulos de renda fixa.

Palavras-chave: Teoria do portfólio. Contratos futuros de commodities. Risco. Retorno.

\section{ABSTRACT}

Objective: To evaluate the effectiveness of the use of commodity futures contracts as a mechanism for optimizing investment portfolios.

Rationale: The study is based on portfolio theory with the premise that investors are risk averse and draw portfolios tangents to the efficiency frontier with the highest expected return for a certain level of risk.

Method: It we composed five portfolios strategies with and without three commodity futures contracts, using the expected returns and the covariance matrix to calculate the asset weights in the portfolios. The analysis contemplates the period 2011-2016 and the sub periods of 2011-2013 and 2014-2016, characterized, respectively, by expansion and economic contraction.

Results: Empirical tests revealed that (i) portfolios with futures contracts offer diversification potential for strategies with higher percentage of the stock market (ii) only portfolios with long position in coffee touched the efficiency zone, while the contracts of cattle and corn did not show evidence of contribution to optimization.; (iii) Portfolios composed mainly of the IFIX, IAM-B, dollar and CDI were the most efficient compositions due to particularities of the Brazilian capital market, such as high interest rate, inflationary environment and exchange depreciation during the period.

Contributions: The results of the study (i) provide insight into the use of commodity futures contracts to reduce investment portfolio risks, (ii) point out that these results may be distinct in times of economic expansion or contraction (iii) corroborates previous studies on the use of commodity futures contracts to optimize stock portfolios, but differentiates when applied to real estate assets and fixed income securities. .

Keywords: Portfolio theory. Commodity futures contracts. Risk. Return.

\section{INTRODUÇÃO}

A teoria do portfólio de Markowitz é considerada um dos pilares das finanças modernas. Sua premissa é de que os investidores são avessos ao risco e, devido a este fator, montam carteiras de investimento eficientes com "média-variância", isto é, portfólios que minimizam o risco para um determinado nível de retorno esperado e que, simultaneamente, maximizam o retorno esperado para um determinado nível de risco (Fama \& French, 2004). Essa teoria fundamenta-se na prática da diversificação das carteiras, introduzindo os conceitos estatísticos de covariância ou correla- 
ção. Segundo Markowitz (1952), é prudente que o investidor evite aplicar seus recursos em ativos que possuem elevado grau de covariância entre eles, sendo adequado montar carteiras com títulos de empresas pertencentes a diferentes setores de atividade.

Com o desenvolvimento do mercado de capitais, surgiram inúmeras inovações para se aplicar o conceito da diversificação com foco na alocação de distintas classes de ativos para composição da carteira ótima: títulos públicos, ações small-caps, ações long-caps, títulos estrangeiros, etc. (Fabozzi, Gupta, \& Markowitz, 2002). Dentre esses instrumentos explorados como forma de diversificação, visando à redução da variância de portfólios, estão os contratos futuros de commodities. Segundo Scherer, He, Fabozzi, Füss e Kaiser (2008), os índices futuros de commodities tendem a ser negativamente auto correlacionados com as ações e títulos, sendo a sua utilização uma maneira de potencializar os ganhos da carteira, o que tem levado ao aumento de interesse dos investidores em compreender os fundamentos estatísticos e econômicos desses instrumentos.

Em âmbito internacional, artigos foram e ainda têm sido elaborados sobre o uso dos índices futuros de commodities para a diversificação do risco. Como exemplo, no estudo de Conover et. al. (2009) foi realizada uma investigação sobre o eficiente de "commodity futures" na diversificação de portfólio, considerando o mercado de capitais americano. Belousova e Dorfleiner (2012) também realizaram uma pesquisa com o mesmo objetivo, porém para o contexto do mercado europeu. Ambos os artigos encontraram benefícios na utilização dos contratos futuros de commodities como forma de diversificação de carteiras. No Brasil, Silveira e Barros (2010) elaboraram um estudo com a mesma temática, considerando o período de 1994-2007. Diferente dos artigos estrangeiros exemplificados, os resultados obtidos com a inclusão de contratos futuros de commodities em portfólios de investimentos não foram considerados significantes. Entretanto, há de se ressaltar que após 2007, tanto o mercado de capitais brasileiro quanto a economia passaram por uma série de transformações, incluindo o uso de derivativos, o que poderia modificar os resultados de uma nova análise.

Nesse contexto, o presente estudo tem por objetivo avaliar a eficácia da utilização de contratos futuros de commodities como mecanismo de otimização das carteiras de investimentos. Procura aprofundar os achados empíricos de outras pesquisas - como o de Silveira \& Barros (2010), por exemplo - sobre o uso de contratos de commodities como instrumento financeiro de diversificação de carteiras no mercado brasileiro.

Considerando a importância das commodities na economia brasileira e o processo atual de utilização de instrumentos financeiros derivativos de commodities, é relevante averiguar seu impacto na redução do risco de portfólios de investimentos. Para verificar se a inclusão de contratos futuros de commodities reduz o risco de um portfólio de investimentos, foram utilizadas ferramentas econométricas e estatísticas para a construção da fronteira de mínima variância e testada a significância da redução do desvio padrão, tido como medida de risco, originada pela utilização dos contratos futuros de commodities nos portfólios de investimentos.

O estudo contribui com o desenvolvimento da literatura a respeito da análise de portfólio de investimentos com o uso de contratos futuros de commodities, principalmente se for considerada a incipiência de estudos com esse foco, principalmente no Brasil - não obstante a relevância desses ativos na economia brasileira. Além de testar a relevância desses contratos como instrumento de gestão de riscos de portfólios, ao segregar o período amostral em subperíodos representativos de períodos de expansão e retração econômica, oferece evidências de que sua utilidade pode ser distinta em função do comportamento do nível de atividade econômica.

O artigo é dividido em mais seis seções, além da introdução: a seção 2 apresenta o referencial teórico, em que é abordado o papel dos contratos futuros de commodities para redução de riscos e diversificação de investimentos, além de outros estudos sobre o assunto. A seção 3 apresenta o desenvolvimento das hipóteses de pesquisa e sua fundamentação teórica. A seção 4 contém os 
procedimentos metodológicos para atender aos objetivos especificados. A seção 5 apresenta a análise de resultados, onde foi analisada a contribuição dos contratos futuros de commodities para as carteiras de investimento. Por fim, a seção 6 apresenta as considerações finais sobre este estudo.

\section{REFERENCIAL TEÓRICO}

\subsection{Gestão de Risco e Instrumentos Derivativos}

O gerenciamento de riscos tornou-se um dos estudos centrais das finanças, em especial devido ao desenvolvimento de novos instrumentos que permitem a mitigação de possíveis perdas de valor de ativos, ou ainda, aumentos no valor de passivos. Parte dos estudos de gestão de riscos foca no uso de derivativos utilizados como ferramentas de proteção a exposição de riscos oriundos de oscilações em taxas de juros, taxas cambiais, preços de commodities e preços de ações (Smith Jr, 2008).

O derivativo pode ser genericamente definido como um contrato privado que tem seu preço derivado de um ativo, índice ou taxa subjacente. A soma dos ganhos e perdas originados deste contrato deve ser igual a zero; para cada ganho obtido por uma parte, a outra parte sofre uma perda de igual magnitude (Jorion, 2007). A princípio, os derivativos são utilizados com a finalidade de hedge, que consiste em uma transação para reduzir ou eliminar a exposição ao risco, protegendo os ativos de movimentos não favoráveis que acarretam a queda do seu valor. Essa proteção é possível porque os derivativos adquiridos possuem seu valor em direção oposta ao instrumento que está sendo hedgeado (Collier, 2009).

O hedge pode ser dividido em duas vertentes. A primeira consiste no hedge estático, representado por contratos futuros e a termo, em que a posição do instrumento derivativo normalmente é mantida até o horizonte do ativo subjacente. Este tipo de hedge é ideal se o preço do derivativo estiver linearmente relacionado com o preço do ativo subjacente. A segunda vertente é o hedge dinâmico, representado pelas opções de ações, em que são feitos balanceamentos durante o horizonte de tempo (Jorion,2003).

Entretanto, além da proteção de perdas, os derivativos passaram a ser vistos também sob a ótica de potencial oportunidade de ganhos, sendo utilizados com a finalidade de especulação, em que sua intenção passa a ser a obtenção de retornos anormais, assumindo riscos elevados (Geczy, Minton, \& Schrand, 2007). A especulação ocorre quando o investidor utiliza o derivativo como uma aposta nas oscilações de variáveis econômicas, uma operação que pode levar a perdas substanciais devido à dificuldade de se prever os movimentos do mercado (Ross, Westerfield, \& Jaffe, 2009).

Dessa forma, a resposta à pergunta se as instituições utilizam os derivativos para especulação ou para hedge ainda não é certa. Esses instrumentos podem levar a perdas substanciais, ultrapassando a tolerância ao risco de seus negócios, e as empresas ainda possuem receio em admitir o caráter especulativo (Smith Jr, 2008).

\subsection{Hedge de Portfólios de Investimentos}

A diversificação de ativos é a forma de hedge mais tradicional de uma carteira de investimentos. Consiste na técnica de elaborar uma carteira com combinação de ativos que possuam covariância negativa, com o objetivo de reduzir a variância do portfólio (Ross, Westerfield \& Jaffe, 2009). A teoria moderna do portfólio sugere que o investidor diversifica sua carteira para eliminar o risco idiossincrático, que é o risco específico do ativo. Como resultado, a carteira fica sujeita ape- 
nas ao risco sistemático, que corresponde ao risco de mercado que não pode ser diversificável, por ser inerente a todas as ações que estão sendo negociadas (Fu, 2009).

O desenvolvimento do mercado financeiro permitiu a criação de novos instrumentos, como os derivativos, que passaram a ser explorados na diversificação de portfólios. Os derivativos, em especial contratos de opções e futuros, são ativos que possuem um papel importante na estruturação de carteiras de ações, por proporcionarem vantagens em relação ao custo-benefício da diversificação (Reilly \& Brown, 2011).

Para ilustrar essa vantagem, Reilly e Brown (2011) apresentam, como exemplo, uma carteira formada por ações que compõem o índice $S \mathcal{E} P$ 500. Caso haja uma previsão de mudanças no cenário macroeconômico, ainda que o portfólio esteja bem diversificado, ele está sujeito ao risco sistemático proveniente de índices inflacionários, por exemplo, podendo haver uma queda do preço de todas as ações. Para se proteger dessas oscilações, o gestor pode utilizar um contrato futuro do índice de $S \mathcal{E} P$ 500, assumindo uma posição de hedge, uma vez que este derivativo é negativamente correlacionado com a exposição existente.

A finalidade do uso de contratos futuros dentro de um portfólio de ações depende do "apetite" ao risco do investidor. Para investidores com um grau maior de aversão ao risco, os contratos futuros são introduzidos apenas visando à mínima-variância, possuindo o mesmo horizonte de tempo do ativo hedgeado, acrescentado de uma correlação perfeitamente negativa. Entretanto, quando considerado o conceito de média-variância, introduz-se o elemento especulativo, de forma que os investidores não estão preocupados apenas com o hedge do risco, mas também com o retorno que pode ser proporcionado pelo contrato futuro na carteira. Nesse caso, o contrato futuro é adquirido para alavancar os retornos esperados e aumentar o prêmio-risco do portfólio (Alexander, 2008).

A utilização do contrato futuro em portfólios de investimentos teve um expressivo aumento a partir de 2002, em especial devido à volatilidade dos preços de commodities, fazendo com que os mercados futuros se aproximassem dos mercados financeiros, transformação denominada de "financialização" dos derivativos (Domanski \& Heath, 2007). Este processo se refletiu em especial na categoria de futuros de commodities, que teve um substancial crescimento em estratégias de investimentos (Belousova \& Dorfleitner, 2012).

Daslaki e Skiadopoulos (2011) defendem que a utilização de contratos futuros de commodities em carteiras aumenta o prêmio-risco, à medida que possibilita reduzir a variância da carteira sem sacrificar o retorno para qualquer que seja o coeficiente de tolerância ao risco. Além disso, os autores acrescentam que os fatores que compõem o preço das commodities (clima, safra, estocagem, extração, tecnologia) se distinguem dos fatores que compõem os preços das ações, fazendo com que estes ativos sejam negativamente correlacionados.

You e Daigler (2013) caracterizam os contratos futuros de commodities como ativos de elevada liquidez, com baixos custos de transação e capazes de proporcionar retornos anormais. Entretanto, os autores alertam que o escopo das pesquisas sobre o assunto ainda é limitado, pois grande parte utiliza índices de commodities, o que não permite com que seja analisado o benefício isolado dos contratos, ou utilizam apenas o efeito de uma categoria de contrato dentro de uma carteira de ativos, o que restringe conclusões sobre a diversificação.

Os estudos de contratos futuros de commodities concentram-se em seu uso com a finalidade de hedge de carteiras de investimentos, havendo um gap nas pesquisas sobre sua utilização com o objetivo de especulação, que pode proporcionar grandes perdas para o investidor (Adam, Fuss \& Kaiser, 2008). Desta forma, os riscos destes instrumentos para estratégias de investimentos não podem ser subestimados. 


\subsection{Risco de Contratos Futuros de Commodities}

As commodities consistem em classes heterogêneas de ativos, de forma que cada espécie possui seu preço conduzido por uma variedade de fatores específicos (Adam, Fuss, \& Kaiser, 2008). Quando considerados seus contratos futuros, o valuation é composto basicamente por fatores macroeconômicos que interferem na sua oferta e demanda e por expectativas dos seus preços futuros e prêmio-risco em suas negociações (Markert \& Zimmermann, 2008).

De acordo com Szymanowska, Roon, Nijman e Goorbergh (2014), o prêmio-risco dos contratos futuros de commodities é derivado do risco de base, que corresponde a diferença entre o preço à vista do ativo subjacente e o seu preço futuro. Este risco é inevitável para os contratos futuros de commodities devido a dois fatores: o primeiro refere-se à incerteza sobre os custos de produção/transporte, somados ao retorno de conveniência do proprietário da commodity que impacta no valor justo de base; o segundo está na incerteza em relação às flutuações dos preços dos contratos futuros no mercado, uma vez que os preços correntes das commodities podem variar significativamente acima dos preços futuros (Alexander, 2008).

O risco de base aumenta com o uso de contratos futuros para especulação, uma vez que quando utilizados com esta finalidade, as características dos contratos futuros se diferenciam das dos ativos subjacentes, de forma que este tipo de operação tende a ser noise nos preços futuros das commodities, influenciando no volume e preço das negociações (Jorion, 2003).

Cao, Jayasuriya e Shambora (2010) analisaram os riscos aos quais as commodities estão submetidas sob a ótica de longo prazo, concluindo que o sucesso do investimento dos futuros de commodities depende, acima de tudo, do aumento do preço da commodity e da replicação desse movimento no mercado futuro, ou então, um aumento contínuo dos preços futuros, independente da commodity subjacente. A oscilação desses preços é algo de difícil previsão, por depender de um conjunto de fatores que interfere diretamente na oferta e demanda desses ativos: variáveis políticas e econômicas, questões climáticas, custos de estocagem, entre outros.

\subsection{Estudos sobre o Mercado Futuro de Commodities no Brasil}

Na literatura acadêmica brasileira, embora exista bolsa de valores própria para negociação de futuros desde 1985, ainda são poucas as pesquisas que exploram a dimensão do contrato futuro de commodity no contexto de finanças. Entre os poucos artigos produzidos acerca do tema, podem ser citados Silveira e Barros (2010), Da Costa e Piacenti (2008) e Bressan e Lima (2009), cada um abordando aspectos distintos em relação a contratos futuros de commodities. A Tabela 1 apresenta uma descrição dos temas, objetivos e resultados encontrados destes artigos: 
Tabela 1: Artigos brasileiros sobre commodities no contexto financeiro

\begin{tabular}{|c|c|c|c|}
\hline Título & Autor(es) & Objetivos & Resultados \\
\hline $\begin{array}{l}\text { Uma análise da alocação de con- } \\
\text { tratos futuros sobre commodities } \\
\text { em portfólios diversificados. }\end{array}$ & $\begin{array}{l}\text { Silveira e Barros } \\
\text { (2010). }\end{array}$ & $\begin{array}{l}\text { Analisar o impacto da utili- } \\
\text { zação de contratos futuros } \\
\text { de commodities agropecuá- } \\
\text { rias no risco e retorno de } \\
\text { uma carteira diversificada do } \\
\text { período de } 1994-2007 \text {. }\end{array}$ & $\begin{array}{l}\text { Não foram encontradas } \\
\text { evidências estatísticas signi- } \\
\text { ficativas na relação risco e } \\
\text { retorno de carteiras com } \\
\text { contratos futuros de commo- } \\
\text { dities. }\end{array}$ \\
\hline $\begin{array}{l}\text { Utilização de Contratos futuros } \\
\text { agropecuários no perfil médio de } \\
\text { investimentos dos fundos de } \\
\text { pensão no Brasil. }\end{array}$ & $\begin{array}{l}\text { Da Costa e Pain- } \\
\text { centi }(2008)\end{array}$ & $\begin{array}{l}\text { Verificar a viabilidade do } \\
\text { uso de contratos futuros de } \\
\text { commodities nas carteiras dos } \\
\text { fundos de pensão brasileiros, } \\
\text { dentro dos limites permiti- } \\
\text { dos, utilizando o modelo } \\
V a R \text {. }\end{array}$ & $\begin{array}{l}\text { A utilização dos contratos } \\
\text { nas carteiras foi benéfica, } \\
\text { reduzindo o risco mais que } \\
\text { proporcionalmente ao re- } \\
\text { torno. }\end{array}$ \\
\hline $\begin{array}{l}\text { Modelos de previsão de preços } \\
\text { aplicados aos contratos futuros de } \\
\text { boi gordo na BM\&F. }\end{array}$ & $\begin{array}{l}\text { Bressan \& Lima } \\
(2009)\end{array}$ & $\begin{array}{l}\text { Aplicar modelos de previsão } \\
\text { de séries temporais como } \\
\text { ferramentas de decisão de } \\
\text { compra e venda de contratos } \\
\text { futuros de boi gordo na } \\
\text { BM\&F em datas próximas do } \\
\text { vencimento. }\end{array}$ & $\begin{array}{l}\text { Os resultados demonstra- } \\
\text { ram o potencial de utiliza- } \\
\text { ção dos Modelos Lineares } \\
\text { dinâmicos e ARIMA como } \\
\text { ferramentas de tomada de } \\
\text { decisão; }\end{array}$ \\
\hline
\end{tabular}

Fonte: Elaborado pelos autores.

\section{DESENVOLVIMENTO DAS HIPÓTESES DE PESQUISA}

O artigo tem como objetivo geral avaliar a eficácia da utilização de contratos futuros de commodities, negociados na B3, como mecanismo de otimização das carteiras de investimentos, isto é, reduzir seu risco (desvio padrão) para determinado nível de retorno.

As hipóteses de pesquisa foram fundamentadas na teoria de diversificação de portfólios de Markowitz. Ao considerar que os contratos futuros de commodities possuem baixa correlação com os ativos financeiros tradicionais devido aos fatores distintos de sua formação de preços (Daskalaki \& Skiadopoulos, 2011; Belousova \& Dorfleitner, 2012), é de se esperar que os contratos sejam capazes de gerar benefícios decorrentes da diversificação e reduzir os desvios das carteiras de investimento. Entretanto, os mercados de commodities caracterizam-se por sua dinamicidade, com oscilações bruscas nos preços e volumes de suas negociações, o que pode acarretar no efeito inverso do esperado.

Jensen et. al. (2000, 2002) apontam que o benefício da diversificação de contratos futuros de commodities só ocorre durante períodos de restrição do ciclo econômico. Tal fator ocorre principalmente devido a relação existente entre o índice inflacionário e o preço das commodities, o que faz com que seus contratos futuros sejam uma forma de proteção frente a períodos de alta inflação. Desta forma, embora Silveira e Barros (2010) não tenham encontrados resultados significantes do uso de contratos futuros no mercado brasileiro, há de se considerar que o período econômico da análise - 1994 a 2007 - distingue-se do atual, o que pode gerar alteração nos resultados encontrados para as hipóteses.

Considerando este contexto, e seguindo Silveira e Barros (2010), foram formuladas quatro hipóteses de pesquisas para os testes empíricos, considerando duas estratégias distintas de investimentos para os contratos.

Inicialmente foram formuladas duas hipóteses, considerando a estratégia de curto prazo, definida como a utilização de contratos futuros de commodities de primeiro vencimento nas cartei- 
ras, ou seja, com o vencimento mais próximo na bolsa. Cada uma das hipóteses é construída para posições de investimento diferentes:

$H_{1}$ : Os contratos futuros de commodities na estratégia de curto prazo, posição de compra, reduzem a volatilidade de carteiras diversificadas de investimentos.

$\boldsymbol{H}_{2:}$ Os contratos futuros de commodities na estratégia de curto prazo, posição de venda, reduzem a volatilidade de carteiras diversificadas de investimentos.

Em seguida foram elaboradas mais duas hipóteses, porém considerando a estratégia de longo prazo, que consiste na utilização de contratos futuros de vencimento de seis meses na bolsa:

$\boldsymbol{H}_{3:}$ Os contratos futuros de commodities na estratégia de longo prazo, posição de compra, reduzem a volatilidade de carteiras diversificadas de investimentos.

$\boldsymbol{H}_{4}$ : Os contratos futuros de commodities na estratégia de longo prazo, posição de venda, reduzem a volatilidade de carteiras diversificadas de investimentos.

\section{METODOLOGIA}

\subsection{Amostra}

Para composição das carteiras de investimentos diversificadas, foram coletadas as cotações diárias de diferentes classes de ativos do período de 04/01/2011 a 30/11/2016. As categorias não pertencentes à classe de derivativos foram selecionadas justamente com base no critério de diversificação, uma vez que pertencem a diferentes nichos do mercado financeiro. A Tabela 2 apresenta os ativos pertencentes à amostra:

Tabela 2: Amostra e fonte dos dados da pesquisa

\begin{tabular}{|l|l|l|}
\hline \multicolumn{1}{|c|}{ Ativo } & \multicolumn{1}{|c|}{ Descrição } & \multicolumn{1}{|c|}{ Fonte } \\
\hline IMA-B & $\begin{array}{l}\text { Índice utilizado como benckmark de títulos de } \\
\text { série B, indexados por juros + IPCA }\end{array}$ & Economática \\
\hline $\begin{array}{l}\text { Certificado de depósito } \\
\text { Interfinanceiro (CDI) }\end{array}$ & $\begin{array}{l}\text { Títulos de curto prazo emitidos por institui- } \\
\text { ções financeiras. Pode ser utilizado como } \\
\text { proxy de um ativo livre de risco. }\end{array}$ & Economática \\
\hline Dólar & Variação cambial do dólar em relação ao real. & Economática \\
\hline Ibovespa (IBOV) & $\begin{array}{l}\text { Índice utilizado para representar uma carteira } \\
\text { teórica formada pelas ações mais negociadas } \\
\text { no mercado. }\end{array}$ & Economática \\
\hline $\begin{array}{l}\text { Índice de Fundos de Inves- } \\
\text { timentos Imobiliários }\end{array}$ & $\begin{array}{l}\text { Indicador de desempenho médio das cotações } \\
\text { dos fundos imobiliários negociados no mer- } \\
\text { cado de bolsa e balcão }\end{array}$ & Economática \\
\hline $\begin{array}{l}\text { Contratos futuros de compra } \\
\text { e venda de commodities }\end{array}$ & $\begin{array}{l}\text { Contratos futuros de boi gordo (BGI), milho } \\
\text { (CCM), café arábica (ICF), soja (SJC), açúcar } \\
\text { (ACF), etanol (ETF), ouro (OZ1), petróleo } \\
\text { (WTI) negociados no mercado de bolsa. }\end{array}$ & Reuters \\
\hline
\end{tabular}

Fonte: Elaborado pelos autores.

Foram utilizados apenas os contratos futuros com liquidez diária na bolsa. Desta forma, verificou-se que apenas os contratos de boi gordo, café arábica e milho atendem ao critério estabe- 
lecido. Uma observação a ser feita é que no período analisado por Silveira e Barros (2010), 19942007, os únicos contratos futuros com liquidez diária eram o boi gordo e café arábica. Nota-se que no período do presente artigo, o contrato do milho passou a ter negociações diárias, sendo um incremento na amostra. Assim, o presente estudo avança em relação a Silveira e Barros (2010), não só em relação ao horizonte temporal, se concentrando em um período caracterizado pela contração econômica, mas também ampliando os ativos considerados no estudo.

Para agrupamento dos dados e montagem dos portfólios, primeiramente foram calculados o retorno médio e desvio padrão. O Ibovespa foi escolhido como a proxy de ações por ser a carteira teórica de maior liquidez e representatividade no mercado de ações brasileiro. Sendo assim, com base nessas considerações, foram construídos cinco portfólios:

a) Carteira composta pela combinação do IBOV, IFIX, IMA-B dólar e CDI.

b) Carteira composta pela combinação do IBOV, IFIX, IMA-B, dólar, CDI e contratos futuros de boi-gordo, café arábica e milho, posição de compra e curto prazo.

c) Carteira composta pela combinação do IBOV, IFIX, IMA-B, dólar, CDI e contratos futuros de boi-gordo, café arábica e milho, posição de compra e longo prazo.

d) Carteira composta pela combinação do IBOV, IFIX, IMA-B, dólar, CDI e contratos futuros de boi-gordo, café arábica e milho, posição de venda e curto prazo.

e) Carteira composta pela combinação do IBOV, IFIX, IMA-B, dólar, CDI e contratos futuros de boi-gordo, café arábica e milho, posição de venda e longo prazo.

As estratégias de curto prazo são compostas por contratos com liquidez diária e vencimento próximo, enquanto as estratégias de longo prazo são compostas por contratos de liquidez diária e vencimento superior a seis meses. O Ibovespa é o principal indicador de performance das ações das empresas de maior importância no mercado brasileiro. O IFIX corresponde ao ativo usado como proxy do mercado imobiliário, sendo um indicador do desempenho médio das cotações dos fundos imobiliários listados na B3. O IMA-B é um índice de renda fixa da família AMBIMA com rentabilidade atrelada ao IPCA, ou seja, retorno remuneração pela inflação. Os Certificados de depósito interbancário são títulos de instituições financeiras com rentabilidade vinculada à taxa DI, que por sua vez acompanha a variação da taxa SELIC. O dólar utilizado corresponde a variação da moeda americana frente à moeda brasileira, sendo uma proxy de um investimento cambial.

\subsection{Tratamento Inicial dos Dados e Estatísticas Descritivas}

Primeiramente são apuradas as estatísticas descritivas dos dados, sendo calculados o retorno médio (mensal), desvio padrão (mensal) e Índice Sharpe. O objetivo deste procedimento é a comparação entre as propriedades risco-retorno e as diferentes classes de ativos da amostra.

O retorno mensal foi obtido pela seguinte fórmula:

Onde:

$$
R_{m}=\frac{P_{i t}}{P_{i t-1}}-1
$$

$R_{m}:$ Retorno médio

$P_{i t}$ : Preço de fechamento no último dia do mês

$P_{i t-1}$ : Preço de abertura do ativo primeiro dia do mês

Há de se ressaltar que para os contratos futuros de posição de venda, foi utilizado o cálculo inverso dos outros ativos, dado por:

$$
R_{m}=\frac{P_{i t-1}}{P_{i t}}-1
$$

Para cálculo do desvio padrão, foi utilizada a fórmula: 
Onde :

$$
s_{i}=\sqrt{\frac{\sum\left(R_{i}-R_{m i}\right)}{n-1}}
$$

$\mathrm{R}_{\mathrm{i}}$ : Retorno do ativo

$\mathrm{R}_{\mathrm{m}}$ : Retorno médio da série do ativo

$\mathrm{n}$ : Número de observações dos retornos (equivalente ao $\mathrm{n}^{\mathrm{o}}$ de dias)

O Índice Sharpe, seguindo Varga (2001), foi obtido por:

$$
I S=\frac{R_{i-} R_{f}}{S_{i}}
$$

Em que $R_{f}$ corresponde ao retorno do ativo livre de risco, correspondente ao CDI.

Para verificar o potencial de diversificação também foi calculada a matriz de correlação entre as variáveis. A correlação é dada por:

$$
r=\frac{\sum_{i=1}^{n}\left(R_{i}-R_{m i}\right)\left(R_{j}-R_{m j}\right)}{\left.\left.\sqrt{\sum_{i=1}^{n}\left(R_{i}\right.}-R_{i m}\right) \sqrt{\sum_{j=1}^{n}\left(R_{j}\right.}-R_{j m}\right)}
$$

\subsection{Método da Construção de Carteiras Eficientes}

Inicialmente foram calculados os retornos diários dos ativos, utilizando a forma logarítmica que assume que os retornos seguem uma distribuição contínua e simétrica, próxima a normal (Soares, Rostagno \& Soares, 2002):

$$
R_{i t}=\ln \left(\frac{R_{i}}{R_{i-1}}\right)
$$

Para os contratos futuros de posição de venda, os retornos diários foram calculados de forma inversa:

$$
R_{i t}=\ln \left(\frac{R_{i-1}}{R_{i}}\right)
$$

Feito os cálculos dos retornos, são elaboradas carteiras eficientes para cada estratégia descrita no tópico da amostra, seguindo o procedimento metodológico de otimização apresentado de DeFusco et. al. (2001). A montagem de carteiras eficientes deve levar em consideração as variáveis de retornos esperados dos ativos e a variância destes retornos, formando a fronteira de mínima variância.

O retorno esperado de um portfólio composto por $n$ ativos é dado pela equação:

$$
E\left(R_{p}\right)=\sum_{j=1}^{n} w_{i} E\left(R_{i}\right)
$$

Onde:

$\mathrm{W}$ : Peso do ativo i dentro da carteira.

Sendo assim:

$$
\sum_{j=1}^{n} w_{i}=1
$$


O início do intervalo de retornos da carteira é representado pelo ativo com a menor média de retorno esperado, enquanto o retorno máximo corresponde ao ativo de maior média.

A variância de um portfólio composto por n ativos é dada por (Ross,Westerfield, \& Jaffe, 2009):

$$
\boldsymbol{\sigma}^{2}=\sum_{i=1}^{n} \sum_{j=1}^{n} w_{i} w_{j} \operatorname{Cov}\left(R_{i}, R_{j}\right)
$$

Para determinar a fronteira de mínima variância para um conjunto de $\mathrm{n}$ ativos, devem ser determinados os retornos esperados mínimos e máximos. Feito isso, são determinados os pesos dos ativos que irão compor o portfólio de mínima variância, que matematicamente significa: Minimizar:

$$
\boldsymbol{\sigma}^{2}=\sum_{i=1}^{n} \sum_{j=1}^{n} w_{i} w_{j} \operatorname{Cov}\left(R_{i}, R_{j}\right)
$$

Sujeito a:

$$
E\left(R_{p}\right)=\sum_{j=1}^{n} w_{i} E\left(R_{i}\right)=r_{\text {min }}<z<r_{\text {max }}
$$

Para fins de comparação e teste de significância dos retornos obtidos entre as carteiras é utilizado o teste de eficiência de portfólio proposto por Gibbons, Ross e Shanken (1989). O teste utiliza o Índice Sharpe - indicador amplamente utilizado na mensuração de otimização de carteiras por ser a razão entre o prêmio e a volatilidade de uma carteira - para mensurar a diferença de eficiência entre duas carteiras. A carteira com o maior Índice de Sharpe é a que toca a fronteira eficiente de investimentos. A relação entre os índices é testada da seguinte maneira:

$$
\mathrm{W}=\left[\frac{\sqrt{1+I S_{i}^{2}}}{\sqrt{1+I S_{j}^{2}}}\right]^{2}-1
$$

Onde:

$I S_{i}^{2}$ : Índice Sharpe da carteira sem contratos

$I S_{j}^{2}$ : Índice Sharpe da carteira com contratos

Em seguida, com o intuito de aplicar o teste estatístico F, é feito o seguinte procedimento:

$$
F=\frac{T(T-n-1)}{n(T-2)} W
$$

Onde:

$T$ : número de observações

$n: \mathrm{n}$ número de portfólios

Desta forma, é realizando o seguinte teste de hipótese:

$\mathrm{H}_{0}=\mathrm{W}$ é igual a 0 ;

$\mathrm{H}_{1}=\mathrm{W}$ é diferente, maior do que 0.

Se $\mathrm{H}_{0}$ for rejeitada, infere-se que a inclusão de contratos futuros melhora a eficiência do portfólio. 


\section{ANÁLISE DE RESULTADOS}

\subsection{Estatísticas Descritivas}

A Tabela 3 apresenta os resultados obtidos dos cálculos das estatísticas descritivas:

Tabela 3: Estatísticas descritivas dos ativos do período de 2011 a 2016

\begin{tabular}{lcccc}
\hline & $\begin{array}{c}\text { Retorno médio } \\
\% \text { a.a }\end{array}$ & Volatilidade & Índice de Sharpe & Assimetria \\
\hline DI & $11,01 \%$ & $0,00 \%$ & - & 0,38 \\
IMA-B & $12,88 \%$ & $2,75 \%$ & 0,68 & 0,035 \\
Dólar & $10,95 \%$ & $14,28 \%$ & $-0,01$ & $-0,13$ \\
IBOV & $-5,22 \%$ & $23,74 \%$ & $-0,68$ & 0,12 \\
IFIX & $11,56 \%$ & $6,86 \%$ & 0,08 & $-1,25$ \\
Milho-short & $1,18 \%$ & $27,5 \%$ & $-0,33$ & 0,61 \\
Boi-short & $6,79 \%$ & $9,6 \%$ & $-0,49$ & 1,31 \\
Café-short & $-16,31 \%$ & $33,1 \%$ & $-0,84$ & 1,14 \\
Milho-long & $4,10 \%$ & $25,25 \%$ & $-0,27$ & $-1,24$ \\
Boi-long & $5,27 \%$ & $25,50 \%$ & $-0,22$ & 0,08 \\
Café-long & $-13.87 \%$ & $32.10 \%$ & -0.77 & 0,41 \\
\hline
\end{tabular}

Fonte: elaborada pelos autores

Uma observação a ser feita é que os contratos futuros da Tabela 3 correspondem aos contratos de posição de compra, sendo que os de posição de venda apresentam retorno e assimetria com sinais inversos e mesmo desvio padrão. O IMA-B e o IFIX foram os únicos ativos que apresentaram retorno maior que o DI, o que resultou em um Índice Sharpe positivo.

Este resultado pode ter sido gerado pela elevada taxa de juros do período, assim como crescimento da inflação. Quando considerados os contratos futuros de commodities, os melhores desempenhos foram os de café na posição vendida, mas, embora tenham os retornos mais elevados, também apresentaram a volatilidade mais alta, o que gerou um Índice Sharpe inferior ao IMA-B. A partir dos dados da Tabela 3, percebe-se também que as commodities apresentaram os menores retornos quando considerada a posição comprada: Os contratos de café seguidos pelos contratos de boi, além de apresentaram os menores retornos, também apresentaram volatilidades elevadas quando comparadas a dos outros ativos. Dos ativos não pertencentes à classe dos contratos futuros, o IBOV apresentou o menor retorno e também a maior volatilidade, indicando o pior desempenho para este grupo.

A Tabela 4 apresenta a matriz de correlação dos ativos da amostra: 
Tabela 4: Matriz de correlação do período de 2013 a 2016

\begin{tabular}{|c|c|c|c|c|c|c|c|c|c|c|c|}
\hline & IBOV & IFIX & DOLAR & IMA-B & DI & $\begin{array}{l}\text { BGI- } \\
\text { SHORT }\end{array}$ & $\begin{array}{l}\text { CCM- } \\
\text { SHORT }\end{array}$ & $\begin{array}{l}\text { ICF- } \\
\text { SHORT }\end{array}$ & $\begin{array}{l}\text { BGI- } \\
\text { LONG }\end{array}$ & $\begin{array}{l}\text { CCM- } \\
\text { LONG }\end{array}$ & $\begin{array}{l}\text { ICF- } \\
\text { LONG }\end{array}$ \\
\hline IBOV & 1,00 & & & & & & & & & & \\
\hline IFIX & 0,01 & 1,00 & & & & & & & & & \\
\hline DOLAR & $-0,05$ & $-0,10^{*}$ & 1,00 & & & & & & & & \\
\hline IMA-B & 0,05 & $0,09^{*}$ & 0,02 & 1.00 & & & & & & & \\
\hline DI & 0.01 & $0,06^{*}$ & 0,00 & $0,06^{*}$ & 1,00 & & & & & & \\
\hline $\begin{array}{l}\text { BGI-curto } \\
\text { prazo }\end{array}$ & $-0,01$ & 0,00 & 0,00 & $-0,01$ & $-0,02$ & 1,00 & & & & & \\
\hline $\begin{array}{l}\text { CCM-curto } \\
\text { prazo }\end{array}$ & $-0,01$ & $-0,04$ & 0,02 & $-0,05$ & 0,01 & 0,02 & 1,00 & & & & \\
\hline $\begin{array}{l}\text { ICF-curto } \\
\text { prazo }\end{array}$ & 0,02 & 0,03 & 0,00 & $0,09^{*}$ & 0,02 & $0,06^{*}$ & 0,02 & 1,00 & & & \\
\hline $\begin{array}{l}\text { BGI-longo } \\
\text { prazo }\end{array}$ & $-0,06^{*}$ & $0,08^{*}$ & 0.02 & $-0,05^{*}$ & 0,01 & $0,22^{*}$ & $-0,03$ & 0,00 & 1,00 & & \\
\hline $\begin{array}{l}\text { CCM-longo } \\
\text { prazo }\end{array}$ & $-0,01$ & $-0,02$ & 0,02 & $-0.07^{*}$ & 0,01 & 0,02 & $0,06^{*}$ & 0,02 & $-0,01$ & 1,00 & \\
\hline $\begin{array}{l}\text { ICF-longo } \\
\text { prazo }\end{array}$ & $-0,01$ & 0,03 & 0,00 & $0,09^{*}$ & 0,02 & $0,06^{*}$ & 0,01 & $0,81^{*}$ & $-0,05$ & 0,01 & 1,00 \\
\hline
\end{tabular}

Novamente, ressalta-se que os contratos da Tabela 4 correspondem à posição de compra, de modo que a posição de venda apresenta coeficiente com sinal inverso. Considerando o coeficiente de correlação de Pearson e sua respectiva significância, observa-se que os coeficientes com sinal positivo entre os contratos futuros e as outras classes de ativos foram inferiores a 0,5 ; o que indica um grau fraco de correlação. O IBOV apresentou coeficiente de correlação negativa com todos os contratos futuros, com exceção do café à curto prazo. Este fator vai de encontro a estudos anteriores, mostrando que as commodities têm potencial de diversificação em relação ao mercado de ações. Quando considerado o grau de confiança de 95\%, apenas o BGI na estratégia de longo prazo apresentou coeficiente negativo significante em relação ao IBOV. Para o IFIX, o ativo que apresentou menor coeficiente de correlação foi o dólar, enquanto que para as commodities, o BGI a longo prazo apresentou coeficiente positivo significativo, porém de baixo grau. O milho, para as duas estratégias, retornou coeficientes negativos em relação ao índice de imóveis. Para o dólar, todas as commodities apresentaram valores positivos próximos a zero, porém nenhum sendo estatisticamente significante. O IMA-B apresentou uma relação inversa com os contratos futuros de boi e milho, sendo que para ambos, na estratégia de longo prazo, os coeficientes foram significantes. Entretanto, em relação ao café, os coeficientes foram positivos e significantes, o que pode ser um indicativo de que esse tipo de ativo, na posição comprada, está exposto às flutuações da inflação, haja vista que a carteira do IMA-B tem índices inflacionários como indexadores. Por fim, o CDI apresentou coeficiente negativo apenas com o contrato de boi a curto prazo, enquanto coeficientes positivos próximos à zero com os outros contratos.

\subsection{Diversificação do Portfólio}

Inicialmente foram elaborados portfólios considerando o período total da amostra, 2011 a 2016, totalizando 107 carteiras, com as seguintes estratégias:

a) Carteira sem contrato: IBOV, IFIX, IMA-B e dólar e CDI. 
b) Carteira com contratos a curto prazo posição comprada: IBOV, IMA-B, IFIX, dólar, CDI, boi gordo (BGI), milho (CCM) e café arábica (ICF).

c) Carteira com contratos a curto prazo posição vendida: IBOV, IMA-B, IFIX, dólar, CDI boi gordo (BGI), milho (CCM) e café arábica (ICF).

d) Carteira com contratos a longo prazo posição comprada: IBOV, IMA-B, IFIX, dólar, CDI boi gordo (BGI), milho (CCM) e café arábica (ICF).

e) Carteira com contratos a longo posição vendida: IBOV, IMA-B, IFIX, dólar, CDI, boi gordo (BGI), milho (CCM) e café arábica (ICF).

O ponto mínimo de retorno foi de 1,83\% a.a., com uma carteira composta apenas pelo IBOV, enquanto o ponto máximo foi de $13,87 \%$ a.a. com uma carteira composta apenas pelo contrato futuro de café vendido. No geral, todas as estratégias com contratos futuros apresentaram menor variância entre os pontos de retorno de $2 \%$ a $10 \%$ ao ano. Entretanto quando considerada a zona de otimização das carteiras baseadas no risco-retorno, as estratégias eficientes se localizaram no intervalo de $10 \%$ a $13 \%$ de retorno, sendo compostas majoritariamente pelo IMA-B, CDI e dólar, com um percentual inferior a $1 \%$ de contrato de café vendido a curto prazo.

Há de se considerar que o preço de commodities iniciou queda progressiva no ano de 2014, gerando alta volatilidade em seus preços, impactando nos contratos futuros. Quando analisada a tabela 3, observa-se que, ainda que os contratos futuros de café na posição vendida tenham sido os ativos de maior retorno, verifica-se também que foram os mais voláteis, razão de terem contribuído para as eficiências das carteiras, porém com participação reduzida.

Dessa forma, apenas a estratégia com contratos futuros vendidos de curto prazo foi eficiente, enquanto as estratégias compotas exclusivamente pelo IFIX, dólar, IMA-B e CDI ofereceram menor risco para o mesmo ponto de retorno das outras três estratégias de contratos futuros. A participação do café vendido variou de $0,17 \%$ no ponto de $11 \%$ de retorno a $0,43 \%$ no ponto de $12,2 \%$ de retorno. Ainda que os contratos do boi e milho não tenham tido participação na zona de eficiência, as estratégias com esses contratos tiveram menor variância que a carteira sem contratos até o ponto de retorno de $10 \%$, em especial por essa última ser composta majoritariamente pelo Ibov, que teve baixo retorno e elevada volatilidade para o período. Quando comparadas apenas as estratégias com contratos futuros, as carteiras com contratos futuros comprados de curto prazo foram as menos eficientes, seguida pela de longo prazo.

Em seguida foi realizado o teste de significância de Gibbons, baseado na diferença estatística do índice de Sharpe entre as carteiras com e sem contratos futuros de commodities. Para os contratos na posição vendida de longo prazo, os resultados foram significantes do intervalo de $9 \%$ a $13 \%$, enquanto de curto prazo de $8 \%$ a 11,00\%, tendo as hipóteses 2 e 4 confirmadas para essas zonas de retorno Os contratos de posição comprada de longo prazo tiveram retorno significante do intervalo de $0 \%$ a 7,5\% e os de curto prazo de $0 \%$ a 5\%, confirmando as hipótese 1 e 3 .

De forma geral, os resultados corroboram com os de Jensen et. al (2000) e Gorton \& Rouwenhorst (2006) por indicar potencial de diversificação com o marcado de ações, uma vez que o uso dos contratos futuros de commodities reduziu o risco de carteiras com percentual elevado do Ibov. Há de se destacar, porém, que conforme Cheung \& Mil (2010), a teoria de otimização do portfólio não se restringe apenas a correlação negativa entre ativos, mas também no conceito de eficiência baseada na relação risco-retorno Essa consideração é fundamental, uma vez que, embora o coeficiente de Pearson tenha evidenciado baixa correlação entre os contratos futuros e o IFIX, IMAB, dólar e CDI , apenas o café na posição vendida indicou melhoria na otimização do portfólio, de forma que as outras estratégias com contratos futuros apresentaram maior risco para retornos iguais ou menores que estratégias compostas majoritariamente por esses quatro ativos. 


\subsection{Análise de Sensibilidade: Diversificação do Portfólio por Ciclo Econômicos}

Como forma de analisar o investimento de contratos futuros de commodities em ciclos econômicos distintos, foi feita uma análise adicional, segregando a amostra em dois subperíodos iguais: 2011-2013 e 2014-2016, caracterizados, respectivamente, por expansão e contração econômica (FGV, 2017). A ideia é promover uma análise de sensibilidade, explorando se os resultados obtidos no período amostral completo apresentam comportamentos distintos ao se restringir a períodos caracterizados por expansão ou retração econômica, considerando que as commodities são ativos que têm seu preço atrelado a condições econômicas. Para a segregação desses períodos, foi considerada como referência a variação do Produto Interno Bruto (PIB): os exercícios que registraram crescimento do PIB (2011-2013) caracterizaram o período de expansão econômica; enquanto os exercícios com variação negativa no nível de atividade econômica (2014-206), o período de retração econômica.

Para o primeiro período, após processamento dos dados, foram elaboradas 114 carteiras, com as seguintes composições:

a) Carteira sem contrato: IBOV, IFIX, IMA-B e dólar e CDI.

b) Carteira com contratos de curto prazo posição comprada: IBOV, IMA-B, IFIX, dólar, CDI e boi gordo (BGI), milho (CCM) e café arábica (ICF).

c) Carteira com contratos de curto prazo posição vendida: IBOV, IMA-B, IFIX, dólar, CDI e café arábica (ICF).

d) Carteira com contratos de longo prazo posição comprada: IBOV, IMA-B, IFIX, dólar, CDI e boi gordo (BGI), milho (CCM) e café arábica (ICF).

e) Carteira com contratos de longo prazo posição vendida: IBOV, IMA-B, IFIX, dólar, CDI boi gordo (BGI), milho (CCM) e café arábica (ICF).

Para o período de 2011-2013, o ICF a curto prazo na posição vendida foi o ativo de maior retorno médio anualizado (23\%), enquanto que sua posição comprada obteve o menor retorno ($23 \%$ ). Dentre os ativos não pertencentes à classe de derivativos, o dólar obteve maior retorno, enquanto o Ibov teve o pior (2,59\%). No segundo período, 2014-2016, dentre os contratos futuros, o BGI comprado a longo prazo teve o maior retorno $(8 \%)$ e sua posição comprada a de menor retorno $(-8 \%)$. Para as outras categorias, o IMA-B $(13 \%)$ teve o maior retorno enquanto o Ibov teve o menor $(5 \%)$.

No primeiro período, todos os portfólios com contratos futuros tiveram menor desvio dentro do intervalo de $0 \%$ a $8 \%$ de retorno. Entretanto há de se destacar que todas as carteiras localizadas nesse espaço foram ineficientes devido ao Ibov, que apresentou volatilidade elevada e rentabilidade baixa, de forma que a redução de sua participação nos portfólios reduziu o desvio e elevou seu retorno gradualmente. Dentre os intervalos de $8,25 \%$ a $12 \%$ de retorno, as carteiras passaram a ser eficientes e majoritariamente compostas pelo CDI, IFIX e IMA-B, que tiveram o melhor desempenho para o período em decorrência principalmente da prática de alta da taxa SELIC, além de serem ativos de menor volatilidade que o mercado de ações.

Considerando desvio e retorno, a carteira mais eficiente foi a de estratégia de contratos futuros de curto prazo na posição vendida e a de posição vendida de longo prazo, ambas devido ao contrato vendido de café. Esse ativo, além de ter reduzido o desvio do portfólio, permitiu com que esse ultrapassasse $12 \%$ de retorno, diferentemente das outras carteiras. Por outro lado, ainda considerando o ponto inicial de $8,25 \%$ de retorno, os outros contratos futuros não tornaram as carteiras nessa região eficientes, não havendo indícios de seu uso como forma de minimizar o risco para o período. Quando verificada a significância estatística dos resultados com base no teste de Gibbons, os resultados foram significantes de $0 \%$ a $8 \%$ para a carteira com contratos comprados de 
custo prazo. Para as carteiras de posição vendida, os resultados foram relevantes a partir do ponto de $8,25 \%$.

No segundo período (2014-2016), apenas as carteiras com contratos futuros vendidos de curto e longo prazo apresentaram menor desvio para o intervalo de retornos de $0 \%$ a $12 \%$, enquanto as carteiras com estratégias de contratos comprados tiveram o maior desvio dentro do intervalo. Diferentemente do primeiro período, os contratos de milho e boi também foram relevantes para a redução do risco das carteiras até o intervalo de $12 \%$. Entretanto considerando a teoria de otimização de portfólios, as carteiras nessa zona de intervalo não foram eficientes, uma vez que apresentaram maior desvio do que as carteiras com retornos entre $12,25 \%$ a $13,6 \%$, compostas majoritariamente pelo dólar, IMA-B, IFIX e CDI. O ponto máximo atingido foi de $13,6 \%$ devido a performance dos fundos imobiliários para o período. Quando aplicado o teste de Gibbons, os resultados tiveram significância estatística apenas para o intervalo de $0 \%$ a $5 \%$, uma vez que para além dessa zona de retorno, o percentual de contratos nas carteiras passou a se próximo a $0 \%$, dando preferência aos outros ativos.

Novamente, foram encontradas evidências do potencial de diversificação das commodities em relação ao mercado de ações. Vários estudos (Erbey \& Harvey, 2006; Idzorek, 2007; Belousova \& Dorfleitner, 2012) apontam que a correlação negativa em relação ao mercado se origina principalmente do uso de commodities como hedge de inflação, uma vez que as ações tendem a ser prejudicadas em ambientes inflacionários, considerando a adoção de medidas restritivas na política monetária. Entretanto, com exceção do café vendido no primeiro período, baseando-se na teoria da otimização, os contratos não melhoraram a relação risco-retorno dos portfólios, haja vista que as estratégias eficientes foram compostas pelo IMA-B, IFIX, Dólar e CDI. O resultado é decorrente de algumas particularidades do mercado brasileiro; primeiramente a rentabilidade do CDI, ativo de desvio próximo a $0 \%$, é atrelada a taxa SELIC que teve uma média de $9 \%$ no primeiro período e $13 \%$ no segundo período. Segundo ponto é que ambos períodos se caracterizam por ambiente de crescimento anual da inflação, fator que beneficia a rentabilidade do IMA-B, carteira de títulos de renda fixa atrelados ao IPCA. Embora as commodities também se beneficiem de choques inflacionários, sua volatilidade é consideravelmente superior a do IMA-B, razão do desempenho do ativo ter superado a performance das commodities. Por fim, IMA-B e CDI possuem baixa correlação, oferecendo potencial de diversificação um com o outro, e são de baixo risco, o que explica serem os ativos de maior percentual na zona de eficiência.

\section{CONCLUSÕES}

O presente artigo teve como objetivo avaliar a eficácia da utilização de contratos futuros de commodities como instrumentos de otimização dos portfólios de investimentos durante o período de 2011 a 2016teira . Para escolha dos contratos futuros inseridos foi utilizado o critério de liquidez diária nas negociações no mercado futuro da B3. Desta forma, foram selecionados para a amostra os contratos de compra e venda de boi gordo, café e milho. Para os ativos não categorizados como derivativos, foram selecionados o IBOV, IMA-B, IFIX, dólar e CDI, cada um representando um nicho distinto do mercado financeiro. A taxa do DI representou o ativo livre de risco para cálculo do Índice Sharpe.

Baseando-se na teoria do portfólio para a análise do período completo, os contratos futuros indicaram potencial de otimização para carteiras compostas majoritariamente pelo Ibov. Esse resultado corrobora com os estudos anteriores, considerando que as commodities são ativos diferenciados, que possuem seu retorno beneficiado por choques inflacionários, uma vez que refletem as expectativas futuras de preços. Por outro lado, os mercados de ações tendem a ser afetados negativamente pela inflação, em especial devido a medidas de política monetária contracionistas, que 
desaquecem a economia. Entretanto, apesar do potencial de diversificação em relação ao mercado de ações, apenas os contratos futuros de café vendidos participaram das estratégias que tocaram a zona de eficiência, uma vez que as carteiras eram compostas majoritariamente pelo IFIX, IMA-B, dólar e CDI. O resultado encontrado é derivado de particularidades da economia brasileira, caracterizada por ciclos inflacionários crescentes e elevadas taxas de juros.

Foi feita uma segunda análise com o propósito de verificar a capacidade de otimização dos contratos futuros para ciclos econômicos distintos. Com isso, baseando-se no CODACE, a amostra foi dividida entre os períodos de 2011-2013, caracterizado por expansão econômica, e 2014-2017, caracterizado por retração econômica. No primeiro período o resultado reforçou o da amostra completa, uma vez que a carteira mais eficiente do período foi composta pelo IFIX, IMA-B, dólar, CDI e contratos de café na posição vendida.

Para o segundo período, as carteiras eficientes foram compostas exclusivamente pelo IFIX, IMA-B, dólar e CDI. Para ambos períodos, as carteiras com contratos futuros melhoraram a relação risco-retorno dos portfólios compostos majoritariamente pelo Ibov, porém não tocaram a zona de eficiência. Sendo assim, as estratégias com contratos futuros, com exceção do café vendido, não foram capazes de superar as estratégias atreladas a ativos com rentabilidade atrelada a juros, inflação e câmbio, em especial devido a elevada volatilidade dos derivativos. Esse resultado pode ser característico de países em desenvolvimento, haja vista que o mercado ainda exige um maior prêmio-risco dos títulos públicos e câmbio dessas economias.

O estudo contribui para a literatura acadêmica brasileira, uma vez que o tema sobre o uso de derivativos de commodities no âmbito de investimentos ainda foi pouco explorado, ainda que as commodities sejam o bem de maior representatividade na economia brasileira. Apesar de convergirem em parte com os de estudos anteriores, os resultados encontrados se apresentam propriedades intrínsecas do mercado brasileiro, como elevada política de taxa de juros e inflação. Dessa forma, sugere-se para estudos futuros a replicação e comparação da pesquisa em outras economias em desenvolvimento, com o objetivo de verificar se há os ativos de renda fixa são capazes de superar as estratégias com contratos futuros. Adicionalmente, também é sugerido um aprofundamento do estudo de causalidade entre variáveis macroeconômicas brasileiras e preços de commodities, com o intuito de verificar o impacto

\section{REFERÊNCIAS}

Adams Z., Fuss, R., Kaiser, D. G. (2008). Macroeconomic determinants of commodity futures returns. The handbook of commodity investing, 87-112.

Alexander, C. (2008). Market Risk Analysis: Pricing, Hedging and Trading Financial Instruments. John Wiley \& Sons.

Belousova, J.; Dorfleitner, G. (2012). On the diversification benefits of commodities from the perspective of euro investors. Journal of Banking \& Finance, 36(9), 2455-2472.

Bressan, A. A., \& de Lima, J. E. (2009). Modelos de previsão de preços aplicados aos contratos futuros de boi gordo na BM\&F. Nova Economia, 12(1).

Cao, B., Jayasuriya, S., Shambora, W. (2010). Holding a commodity index fund in a globally diversified portfolio: a placebo effect? Economics Bulletin 30, 1842- 1851.

Cheung, C. S., \& Miu, P. (2010). Diversification benefits of commodity futures. Journal of International Financial Markets, Institutions and Money, 20(5), 451-474.

Collier, P. M. (2009). Fundamentals of risk management for accountants and managers. Routledge. 
Conover, C. M., Jensen, G. R., Johnson, R. R., \& Mercer, J. M. (2010). Is now the time to add commodities to your portfolio?. The Journal of Investing, 19(3), 10-19.

Da Costa, T. M. T., \& Piacenti, C. A. (2008). Utilização de Contratos futuros agropecuários no perfil médio de investimentos dos fundos de pensão no Brasil. Revista Contabilidade E Finanças, 19(46), 59-72.

Daskalaki, Charoula, \& Skiadopoulos, George (2011). Should investors include commodities in their portfolios after all? New evidence. Journal of Banking \& Finance, 35(10), 2606-2626.

DeFusco, R. A., Mcleavey, D. W., Pinto, J. E., Runkle, D. E., \& Anson, M. J. (2015). Quantitative investment analysis. John Wiley \& Sons.

Domanski, D., \& Heath, A. (2007). Financial investors and commodity markets. BIS Quarterly Review, 53-67.

Erb, C. B., \& Harvey, C. R. (2006). The strategic and tactical value of commodity futures. Financial Analysts Journal, 62(2), 69-97.

Fabozzi, F. J., Gupta, F., \& Markowitz, H. M. (2002). The legacy of modern portfolio theory. The Journal of Investing, 11(3), 7-22.

Fama, E. F., \& French, K. R. (2004). The capital asset pricing model: Theory and evidence. The Journal of Economic Perspectives, 18(3), 25-46.

Fundação Getúlio Vargas [FGV] (2017, outubro). Comitê de Datação de Ciclos Econômicos (CODACE). Recuperado de http://portalibre.fgv.br/lumis/portal/file/fileDownload.jsp?fileId=8A7C82C55EC04CF1015FE89DE $\underline{84 \mathrm{D} 289 \mathrm{C}}$

Fu, F. (2009) Idiosyncratic risk and the cross-section of expected stock returns. Journal of Financial Economics, 91(1), 24-37.

Géczy, C. C., Minton, B. A., \& Schrand, C. M. (2007). Taking a view: Corporate speculation, governance, and compensation. The Journal of Finance, 62(5), 2405-2443.

Gibbons, M. R., Ross, Stephen A., SHANKEN, J. (1989). A test of the efficiency of a given portfolio. Econometrica: Journal of the Econometric Society, 57(5), 1121-1152.

Gorton, G., \& Rouwenhorst, K. G. (2006). Facts and fantasies about commodity futures. Financial Analysts Journal, 62(2), 47-68.

Idzorek, T. M. (2007). Commodities and strategic asset allocation. Intelligent commodity investing, 113-177.

Jensen, G. R., Johnson, R. R., \& Mercer, J. M. (2000). Efficient use of commodity futures in diversified portfolios. Journal of Futures Markets, 20(5),489-506.

Jorion, P. (2007). Financial risk manager handbook. John Wiley $\mathcal{E}$ Sons.

Markert, V., \& Zimmermann H. (2008). The relationship between risk premium and convenience yield models. John Wiley \& Sons.

Markowitz, H. (1952). Portfolio selection. The journal of finance, 7(1), 77-91.

Reilly, F. K., \& Brown, K. C. (2011). Investment analysis and portfolio management. Cengage Learning. 
Ross,Westerfield, \& Jaffe. (2009). Corporate finance. McGraw-Hill.

Scherer, B., He, L., Fabozzi, F. J., Füss, R., \& Kaiser, D. G. (2008). The Diversification Benefits of Commodity Futures Indexes: A Mean-Variance Spanning Test. The Handbook of Commodity Investing, 241-265.

Silveira, R. L. F. da; Barros, G. S. C. (2010). Uma análise da alocação de contratos futuros sobre commodities em portfólios diversificados. Revista de Economia e Sociologia Rural, 48(1), 195-222.

Szymanowska, M., Roon, F., Nijman, T., \& Goorbergh, R. (2014). An anatomy of commodity futures risk premia. The Journal of Finance, 69(1), 453-482.

Varga, G. (2001). Índice de Sharpe e outros indicadores de performance aplicados a fundos de ações brasileiros. Revista de Administração Contemporânea, 5(3), 215-245.

You, L., \& Daigler, R. T. (2013). A Markowitz optimization of commodity futures portfolios. Journal of Futures Markets, 33(4), 343-368. 